\title{
Multi-drug resistance and other predictors for mortality in severe sepsis and sepsis chock due to Gram-negative and Gram-positive pathogens in a tertiary care hospital in Brazil: a retrospective matched case vs case vs control study design
}

DOI: $10.46919 / \operatorname{archv2n3-002~}$

Recebimento dos originais: 01/04/2021

Aceitação para publicação: 31/06/2021

\section{Sebastiana Silva Sabino}

MSc

Universidade Federal de Uberlândia, Faculdade de Medicina, Uberlândia, MG, Brasil.

E-mail: ssilvasabino@yahoo.com.br

\section{Paola Amaral de Campos}

$\mathrm{PhD}$

Universidade Federal de Uberlândia, Instituto de Ciências Biomédicas, Uberlândia, MG, Brasil.

E-mail: pa.camposs@hotmail.com

\section{Luiz Gustavo Machado}

MSc

Universidade Federal de Uberlândia, Instituto de Ciências Biomédicas, Uberlândia, MG, Brasil.

E-mail: machado.lug@gmail.com

Caio Augusto de Lima

Universidade Federal de Uberlândia, Faculdade de Medicina, Uberlândia, MG, Brasil.

E-mail: caioaugustodelima@yahoo.com.br

\section{Astrídia Marília de Souza Fontes $\mathrm{PhD}$}

Universidade Federal de Uberlândia, Faculdade de Medicina, Uberlândia, MG, Brasil.

E-mail: astridia.fontes@ufu.br

\section{Paulo Pinto Gontijo-Filho}

$\mathrm{PhD}$

Universidade Federal de Uberlândia, Faculdade de Medicina, Uberlândia, MG, Brasil.

E-mail: gontijofilho@ufu.br

\section{Rosineide Marques Ribas $\mathrm{PhD}$}

Universidade Federal de Uberlândia, Faculdade de Medicina, Uberlândia, MG, Brasil.

Corresponding author: Dra. Rosineide M. Ribas, Universidade Federal de Uberlândia, Departamento de

Clínica Médica. Av. Pará, 1720, Umuarama, Uberlândia MG, 38405-320, Brasil.

E-mail: rosi_ribas@yahoo.com.br 


\begin{abstract}
Introduction: Infections, mainly bloodstream infections (BSI), acquired in the intensive care unit (ICU) are associated with significant rates of morbidity and mortality, especially when caused by pathogens. The objectives the study were to determine risk factors and mortality rates in 30 days for patients with BSI caused by microorganisms resistant versus microorganisms susceptible to antimicrobials. Methods: A case- $v s$-control study was carried out, in which patients were identified with BSI acquired in the ICU. Control patients were paired, considering: age, acute mean severity classification (ASIS), and chronic disease scores, Charlson's Comorbidity Index (CHARLSON) both $\geq 3$. Results: Retrospective cohort study of 531 patients, 254 with bloodstream infection (BSI), and 277 uninfected controls during hospital stay. Of those infected, 181 presented multidrug-resistant isolates (MDR) and 73, isolates susceptible to antibiotics. The univariate analysis showed statistically significant frequencies for BSIs, when compared with controls, of isolates resistant to multiple drugs and susceptible. There was also significance in the mortality rate among patients with resistant and susceptible pathogens $(40.3 \%$ vs $34.2 \%, P<0.05)$. Multivariate analysis showed that only trauma and previous use of antibiotics were independent risk factors for BSIs in critically ill patients with infection, both by MDR and antibiotic-sensitive isolates. Conclusion: Mortality and bacteremia were higher in BSIs due to antibiotic-resistant isolates in a cohort of intensive care patients. The lack of financial and human resources results in multiple barriers in developing countries like Brazil and the prevention of these infections becomes a major challenge.
\end{abstract}

Keywords: Healthcare-associated infection, Intensive Care Units, Epidemiology, Risk factors, Bloodstream infection.

\title{
1 INTRODUCTION
}

Antimicrobial resistance is a growing challenge in the care of critically ill patients, among whom the burden of infections remains high and is significantly higher in countries with limited resources, such as Brazil ${ }^{1,2}$. Infections caused by resistant pathogens are difficult to treat and are associated with increased morbidity, mortality, and healthcare costs $3,4,5$.

Endemic infections associated with healthcare, as well as antimicrobial resistance, represent a major and safety problem for hospitalized patients in developing countries, displaying greater epidemiological relevance than in the developed countries ${ }^{6}$. The difference between developed and developing countries is even more evident when we consider the incidence of infections in patients admitted to intensive care units (ICUs). For example, pooled data from some low- and middle-income countries indicate densities 16- to 19-fold higher for catheter-related bloodstream infections and ventilator-associated pneumonia, respectively ${ }^{7}$.

Bacteremias are classified as primary, especially when associated with the use of central venous catheters (CVC), and secondary, when the focus of infection is located outside the vascular system ${ }^{8}$. The most commonly reported causative pathogens for hospital acquired bloodstream infections (BSI) associated with CVC comprise Staphylococcus coagulase negative (SCoN), Staphylococcus aureus, enterococci, and Candida spp. ${ }^{9}$, while Gram-negative Bacilli (GNB) account for around $20 \%$ of catheter associated BSIs as reported by the Centers for Disease Control and Prevention ${ }^{10}$. This study was carried out to determine the 
risk factors and 30-day mortality rates for BSI caused by multi-drug resistant microorganisms versus susceptible microorganisms.

\section{METHODS}

\subsection{SCENARIO AND STUDY PROJECT}

Retrospective case-case-control study carried out from January 2012 to December 2014 at a Clinical Hospital, a large medical university center, with an adult clinical-surgical ICU with 30 beds, located in Uberlandia, MG, southeastern Brazil.

All patients admitted to the ICU during the study period with positive blood culture 48 hours after admission to the Unit were registered. The outcome variable evaluated was hospital mortality. This case$v s$-control study, in which cases were identified with BSI acquired in the ICU (first episode of BSI in $\leq 48$ $\mathrm{h}$ after admission to the ICU). Control patients were paired considering the absence of a BSI positive culture acquired in the ICU during hospitalization. Patients were paired (1:1 / 1:2 cases $v s$ controls), adjusted for demographic characteristics, age ( \pm 10 years) gender, acute disease severity score, Average Severity Rating (ASIS $\geq 3$ ), and patients were seen in the same period ( \pm 30 days) at the unit. The following variables were considered: trauma, surgery, length of stay in the UTI, mechanical ventilation, central venous catheter, bladder catheter, surgical drain, tracheostomy, hemodialysis, parenteral nutrition, previous antibiotic therapy in the unit and inadequate empirical antibiotic therapy.

The 30-day total crude mortality rates between cases (resistant isolates vs. antibiotic-sensitive isolates) vs control patients were also compared between the two groups. The blood isolates were identified by Vitek®, as well as the following pathogens of antibiotic-resistant were evaluated by the hospital's microbiology laboratory: Methicillin-resistant Staphylococcus aureus (MRSA), Methicillin-resistant coagulase-negative staphylococci (CoNS), vancomycin-resistant enterococci (VRE), Enterobacteriaceae that produce extended-spectrum beta-lactamases, mainly third and fourth generation cephalosporins (ESBLs) and carbapenem-resistant Acinetobacter baumannii, Pseudomonas aeruginosa and other nonfermenting Gram-negative bacilli isolates.

\subsection{DATA COLLECTION AND DEFINITIONS}

Patients who met the National Healthcare Safety Network (NHSN) ${ }^{11}$ and ANVISA ${ }^{12}$ criteria for hospital-acquired infections were included in the study. Antimicrobial (empirical/definitive) treatment was considered as the inappropriate antimicrobial therapy (AMT) when the initially prescribed antibiotic regimen was inactive against the pathogen identified based on an in vitro susceptibility test and "in vitro" and/or was administered after 24 hours blood cultures results ${ }^{13}$. The study was approved by the University 
Ethics Committee and informed consent was waived (protocol number 1627/990 - 2016), since the data collection was retrospective, without any information identifying the assessed patients.

\subsection{STATISTICAL ANALYSIS}

Continuous variables were compared using Student's t-test. The $\chi^{2}$ test was used to compare categorical variables. All calculations were performed using the SPSS software (PC version 11.0, Chicago, US) and GraphPad Prism 8.0 (GraphPad Software, Inc., San Diego, CA). Statistical significance was set at $P<0.05$.

\section{RESULTS}

The study involved a total of 531 patients, 254 infected by resistant / susceptible microorganisms and, 277 uninfected controls. The majority in the cohort (71.2\%) the BSI was due to antibiotic-resistant pathogens. Overall, the most common isolates were identified as (CoNS) (40.5\%, 103/254) followed by Pseudomonas aeruginosa $(6.7 \%, 17 / 254)$ and Staphylococcus aureus $(5.9 \%, 15 / 254)$. Overall, most of the infections were caused by Gram-positive cocci $(48.8 \%, 124 / 254)$ and around one fifth of the BSIs $(21.2 \%$, 54/254), was associated with a mixed etiology. These data are presented in the Table 1.

The 30-day mortality among patients with BSIs due to resistant isolates was $40.3 \%$, compared to $12.5 \%$ among those without infection $(P<0.0001, \mathrm{OR}=3.5)$. The mortality rate was also higher in those infected by sensitive isolates being, $34.2 \%$ vs $11.8 \%$ in the control group $(P=0.0086, O R=2.9)$ (Tables 2 and 3). However, these two groups with respectively $40.3 \%$ (resistant isolates) $v s 34.2 \%$ (sensitive isolates) showed similar rates without a static difference $(P=0.0011$ and $P=0.0035)$ when compared among them (Tables 2 and 3).

Several risk factors associated with BSI caused by susceptible and resistant organisms are shown respectively in tables 2 and 3. In both groups of patients, most risk factors were present by univariate analysis. However, a logistic regression analysis of these variables associates with 30-day mortality only trauma for BSIs caused by antibiotic-resistant organisms $(\mathrm{OR}=4.3,95 \% \mathrm{CI} 2.3$ to $8.0, P<0.001)$ and sensitive-isolates $(\mathrm{OR}=3.3,95 \% \mathrm{CI} 1.5$ to $7.2, P=0.0032)$ and previous antibiotic use with $\mathrm{OR}=4.1,95 \%$ CI 1.8 to $9.2, \mathrm{P}=0.007$, for resistant isolates, and $\mathrm{OR}=3.6,95 \% \mathrm{CI} 1.1$ to $12.1, P=0.00361$ for susceptible isolates were predictors of mortality. In patients presenting infections caused by susceptible organisms' chronic renal infection was also a predictor of BSIs (Table 3).

Patients with infections associated with resistant isolates remained hospitalized about two times longer (2.785 days) than when the infections were due to susceptible organisms (1.137 days) statistically more significant $(P=0.0001)$ than their respective controls (1.837 days and 834 days) (Tables 2 and 3$)$. The 
mean of length of stay of these two groups compared with the controls were, respectively $15.4 v s 9.6$ days and 15.4 vs 9.8 days.

\section{DISCUSSION}

Sepsis is the most common cause of death among critically ill patients in clinical-surgical intensive care units ${ }^{14}$ and treatment is considered the most expensive in hospitals ${ }^{15}$. However, the epidemiology and cost of BSI data from developed countries with limited resources are scarce in the literature and in developing countries like Brazil these data are largely unavailable ${ }^{16,17}$. In these countries, there is considerable heterogeneity between hospitals ${ }^{14,18}$.

In addition, we analyzed whether infections due to multidrug-resistant pathogens were associated with an increased length of hospital stay compared to those caused by sensitive pathogens. Healthcareassociated infections (HAIs) are serious problems for patient safety in intensive care units (ICUs). Thereafter, a high proportion of these infections occur in the ICU, with a rate greater than $30 \%$ of all ICU admissions. ICU patients are prone to infection due to reduced host defense mechanisms caused by the severity of the disease, underlying diseases (diabetes, cancer, etc.), the presence of various invasive devices, resulting in the rupture of anatomical and protective barriers immunological and administration of various drugs.

Furthermore, the use of broad-spectrum antimicrobial agents leads to the emergence of multidrugresistant organisms. On the other hand, due to the heavy workload and low personnel rates, health professionals working in ICUs have little adherence to hand hygiene and other basic measures of infection prevention and control (IPC), resulting in cross-infection of microorganisms from patient to patient ${ }^{1}$. For various reasons, in low to middle income countries, the scale of the problem is enormous; each year, more people die from HAIs than from breast and prostate cancer, traffic accidents, or war in these countries ${ }^{2,3}$.

Due to the high morbidity and mortality caused by these infections, early diagnosis and treatment of these infections with appropriate antibiotics are essential. Santos Filho et al $(2020)^{19}$ indicated that the treatment performed with antibiotic therapy showed positive outcomes in all cases, contrary to what is presented here. Furthermore, in our work, the epidemiology of HAIs and infection prevention and control measures in ICUs are discussed, with special emphasis on LMICs. According to the World Bank's Atlas method (2015), (http://data.worldbank.org/), low-income economies are defined as those with a gross national income (GNI) per capita of \$1,045 or less in 2013; Middle-income economies are those with a GDP per capita of more than $\$ 1,045$, but less than $\$ 12,746$; and high-income economies are those with GNI per capita of $\$ 12,746$ or more. Low- and upper-middle-income economies are separated by a GDP per capita of $\$ 4,125$. 
Analyzing and determining the impact of BSI in countries with limited resources is a major challenge. The results of the present study corroborate previous studies reporting a high burden of these infections in hospital settings ${ }^{1,2}$. The microbiology data from BSI indicate a high prevalence of Staphylococcus spp. coagulase-negative. (SCoN) when compared to GNB (83.8\% vs 29.9\%). These data are in agreement with other studies, mainly in developing countries like Brazil ${ }^{20,21}$. This may be associated with the spread of these microorganisms and / or failures in infection control and preventive measures ${ }^{22,23,24}$.

The SENTRY study in the United States and European assessments, as well as other studies in Latin America, indicate high frequencies of oxacillin-resistant MRSA as nosocomial agents ${ }^{25}$. However, in our study, MRSA was responsible for only $8.9 \%$ of BSI cases, with MRSE as the predominant agent, $91.1 \%$. Special attention has been given to the resistance of microorganisms to broad-spectrum antimicrobials, considering the significant and rapid increase in resistance observed and reported in ICUs in developing countries $^{23}$ This is particularly worrying, as therapeutic options are becoming scarce and / or ineffective $\mathrm{e}^{26,27}$.

Infections, including BSIs caused by resistant or multidrug-resistant pathogens are associated with increased morbidity, mortality, length of hospital stay and health costs $28,29,30,31$. Our results also indicate that, regardless of whether the infection was caused by resistant or susceptible microorganisms, higher statically significant rates were observed for morbidity and mortality rates, but the length of stay was the same (15.4 days).

However, the risk factors in both groups were similar. Normally, studies mainly from countries with fewer resources report that patients with BSI due to resistant or multidrug microorganisms are more frequent when compared to patients who have an infection with susceptible microorganisms ${ }^{32}$, similar to our data, with respectively, $71.25 \%(181 / 254)$ vs $28.74 \%(73 / 254)$.

The multivariate analysis showed that both groups had trauma and previous use of antibiotics as the only predictors and BSIs had nephropathy as co-morbidity and the hemodialysis procedure was significant, respectively for BSIs by resistant and susceptible isolates.

Trauma is the main risk factor for $\mathrm{HAI}^{33,34,35}$, half of our cohort was admitted to the ICU due to traffic and work accidents $(50.00 \%, 127 / 254)$. In total, the mortality rate and length of stay in the unit for both groups (resistant and susceptible isolates) were statistically significant, higher (mortality) and longer (LOS) for patients with BSIs due to multi-resistant organisms.

\section{CONCLUSION}

In summary, mortality and bacteremia were higher in BSIs due to antibiotic-resistant isolates in a cohort of intensive care patients. High hospital infection rates, especially BSI due to resistant pathogens, is a serious problem in ICU in low to middle-income countries (LIMICs) as Brazil, mainly in critical care units of big and teaching affiliated hospitals. In view of the increased prevalence of multidrug resistant 
microorganisms, LIMICs should establish effective infection prevention and control (IPC) infrastructure, appoint IPC teams, and provide adequate training and resources to implement basic IPC measures, such as adherence to hand hygiene and care package implementation.

\section{CONFLICT OF INTEREST STATEMENT}

All authors declare that there are no conflicts of interest relevant to this article.

\section{FINANCIAL SUPPORT}

The authors thank FAPEMIG, CNPQ and CAPES for the financial support. 


\section{REFERENCES}

1. Vilar-Compte D, Camacho-Ortiz A, Ponce-de-León S. Infection control in limited resources countries: challenges and priorities. Curr Infect Dis Rep. 2017;19(5):20.

2. Vincent JL, Rello J, Marshall J, Silva E, Anzueto A, Martin CD, et al. International study of the prevalence and outcomes of infection in intensive care units. JAMA. 2009;302(21):2323-2329.

3. Kuti EL, Patel AA, Coleman CI. Impact of inappropriate antibiotic therapy on mortality in patients with ventilator-associated pneumonia and blood stream infection: a meta-analysis. J Crit Care. 2008;23(1):91100.

4. Giske CG, Monnet DL, Cars O, Carmeli Y. Clinical and economic impact of common multidrug-resistant gram-negative bacilli. Antimicrob Agents Chemother. 2008;52(3):813-821.

5. Schwaber MJ, Carmeli Y. The effect of antimicrobial resistance on patient outcomes: importance of proper evaluation of appropriate therapy. Crit Care. 2009;13(1):106.

6. Allegranzi B, Nejad SB, Combescure C, Graafmans W, Attar H, Donaldson L, Pittet D. Burden of endemic health-care-associated infection in developing countries: systematic review and meta-analysis. Lancet. 2011;377(9761):228-241.

7. Rosenthal VD, Bijie H, Maki DG, Mehta Y, Apisarnthanarak A, Medeiros EA, et al. International Nosocomial Infection Control Consortium (INICC) report, data summary of 36 countries, for 2004-2009. Am J Infect Control. 2012;40(5):396-407.

8. O'grady NP, Alexander M, Burns LA, Dellinger EP, Garland J, Heard SO, et al. Guidelines for the prevention of intravascular catheter-related infections. Clin Infect Dis. 2011;52(9):e162-e193.

9. Wisplinghoff H, Bischoff T, Tallent SM, Seifert H, Wenzel RP, Edmond MB. Nosocomial bloodstream infections in US hospitals: analysis of 24,179 cases from a prospective nationwide surveillance study. Clin Infect Dis. 2004;39(3):309-317.

10. Weinstein RA, Gaynes R, Edwards JR, \& National Nosocomial Infections Surveillance System. Overview of nosocomial infections caused by gram-negative bacilli. Clin Infect Dis. 2005;41(6):848-854.

11. Horan TC, Andrus M, Dudeck MA. CDC/NHSN surveillance definition of health care-associated infection and criteria for specific types of infections in the acute care setting. Am $\mathrm{J}$ Infect Control. 2008;36(5):309-332.

12. Agência Nacional de Vigilância Sanitária (BR). Segurança do Paciente e Qualidade em Serviços de Saúde: Critérios Diagnósticos de Infecção Relacionada à Assistência à Saúde. 2. ed. v. 2. Brasília (DF): Anvisa; 2017. 89 p.

13. Zilberberg MD, Shorr AF, Micek ST, Vazquez-Guillamet C, Kollef MH. Multi- drug resistance, inappropriate initial antibiotic therapy and mortality in Gram-negative severe sepsis and septic shock: a retrospective cohort study. Crit Care. 2014;18(6):596. 
14. Angus DC, Linde-Zwirble WT, Lidicker J, Clermont G, Carcillo J, Pinsky MR. Epidemiology of severe sepsis in the United States: analysis of incidence, outcome, and associated costs of care. Crit Care Med. 2001;29(7):1303-1310.

15. Torio CM, Andrews RM. National Inpatient Hospital Costs: The Most Expensive Conditions by Payer, 2011: HCUP Statistical Brief \#160. Agency for Healthcare Research and Quality, Rockville, MD., August 2013.

16. Martin GS, Mannino DM, Eaton S, Moss M. The epidemiology of sepsis in the United States from 1979 through 2000. N Engl J Med. 2003;348(16):1546-1554.

17. Moerer O, Schmid A, Hofmann M, Herklotz A, Reinhart K, Werdan K, et al. Direct costs of severe sepsis in three German intensive care units based on retrospective electronic patient record analysis of resource use. Intensive Care Med. 2002;28(10):1440-1446.

18. Nangino GO, Oliveira CD, Correia PC, Machado NM, Dias ATB. Financial impact of nosocomial infections in the intensive care units of a charitable hospital in Minas Gerais, Brazil. Rev Bras Ter Intensiva. 2012;24(4):357-361.

19. SANTOS FILHO, Carlos Augusto Moura; ARAGÃO, Matheus Todt; SANTOS, Rayanna Souza. Perfil clínico e epidemiológico de infecções relacionadas às próteses articulares. Archives of Health, v. 1, n. 1, p. 7-16, 2020.

20. Silva E, Dalfior LJ, Fernandes SH, Moreno R, Vincent JL. Prevalence and outcomes of infections in Brazilian ICUs: a subanalysis of EPIC II study. Rev Bras Ter Intensiva, 2012;24(2):143-150.

21. Weiner LM, Webb AK, Limbago B, Dudeck MA, Patel J, Kallen AJ, et al. Antimicrobial-resistant pathogens associated with healthcare-associated infections: summary of data reported to the National Healthcare Safety Network at the Centers for Disease Control and Prevention, 2011-2014. Infect Control Hosp Epidemiol. 2016;37(11):1288-1301.

22. Dudeck MA, Weiner LM, Allen-Bridson K, Malpiedi PJ, Peterson KD, Pollock DA, et al. National Healthcare Safety Network (NHSN) report, data summary for 2012, device-associated module. Am J Infect Control. 2013;41(12):1148-1166.

23. Alp E, Damani N. Healthcare-associated infections in intensive care units: epidemiology and infection control in low-to-middle income countries. J Infect Dev Ctries. 2015;9(10):1040-1045.

24. Bardossy AC, Zervos J, Zervos M. Preventing hospital-acquired infections in low-income and middleincome countries: impact, gaps, and opportunities. Infect Dis Clin North. 2016;30(3):805-818.

25. Sader HS, Castanheira M, Farrell DJ, Flamm RK, Mendes RE, Jones RN. Tigecycline antimicrobial activity tested against clinical bacteria from Latin American medical centres: results from SENTRY Antimicrobial Surveillance Program (2011-2014). Int J Antimicrob Agents. 2016;48(2):144-150.

26. Gales AC, Castanheira M, Jones RN, Sader HS. Antimicrobial resistance among gram-negative bacilli isolated from Latin America: results from SENTRY Antimicrobial Surveillance Program (Latin America, 2008-2010). Diagn Microbiol Infect Dis. 2012;73(4):354-360. 
27. Rossi F, Girardello R, Cury AP, Di Gioia TSR, de Almeida Jr JN, da Silva Duarte AJ. Emergence of colistin resistance in the largest university hospital complex of São Paulo, Brazil, over five years. Braz J Infect Dis. 2017;21(1):98-101.

28. Kollef MH, Ward S, Sherman G, Prentice D, Schaiff R, Huey W, Fraser VJ. Inadequate treatment of nosocomial infections is associated with certain empiric antibiotic choices. Crit Care Med. 2000;28(10):3456-3464.

29. Cosgrove SE, Qi Y, Kaye KS, Harbarth S, Karchmer AW, Carmeli Y. The impact of methicillin resistance in Staphylococcus aureus bacteremia on patient outcomes: mortality, length of stay, and hospital charges. Infect Control Hosp Epidemiol. 2005;26(2):166-174.

30. Engemann JJ, Carmeli Y, Cosgrove SE, Fowler VG, Bronstein MZ, Trivette SL, et al. Adverse clinical and economic outcomes attributable to methicillin resistance among patients with Staphylococcus aureus surgical site infection. Clin Infect Dis. 2003;36(5):592-598.

31. Neidell MJ, Cohen B, Furuya Y, Hill J, Jeon CY., Glied S, Larson EL. Costs of healthcare-and community-associated infections with antimicrobial-resistant versus antimicrobial-susceptible organisms. Clin Infect Dis. 2012;55(6):807-815.

32. Leal HF, Azevedo J, Silva GEO, Amorim AML, de Roma LRC, Arraes ACP, et al. Bloodstream infections caused by multidrug-resistant gram-negative bacteria: epidemiological, clinical and microbiological features. BMC Infect Dis. 2019;19(1):609.

33. Wafaisade A, Lefering R, Bouillon B, Sakka SG, Thamm OC, Paffrath T, et al. Epidemiology and risk factors of sepsis after multiple trauma: an analysis of 29,829 patients from the Trauma Registry of the German Society for Trauma Surgery. Crit Care Med. 2011;39(4):621-628.

34. Valencic L, Tokmadzic VS, Kuharic J, Sustic A. The incidence of nosocomial infections in patients with isolated severe traumatic brain injury. Sanamed. 2015;10(3):185-194.

35. Maas AI, Stocchetti N, Bullock R. Moderate and severe traumatic brain injury in adults. Lancet Neurol. 2008;7(8):728-741. 